\title{
Uma tradução oitocentista inédita da décima sátira de Juvenal
}

Fábio Paifer Cairolli ${ }^{1}$

\begin{abstract}
Resumo: O presente artigo visa apresentar a transcrição do manuscrito inédito de uma tradução da décima sátira de Juvenal para o português, empreendida em meados do século XIX pelo médico, poeta, professor e tradutor ítalo-brasileiro Luiz Vicente de Simoni (1792-1881). Além de apresentar as questões de crítica textual que contextualizam o documento, serão tecidos alguns comentários referentes ao mérito da tradução, contrastando-a com a versão lusitana de Francisco Antonio Martins Bastos, tradutor contemporâneo cuja versão é mais conhecida.
\end{abstract}

Palavras-chave: Juvenal; tradução poética; Luiz Vicente de Simoni (17921881); transcrição diplomática.

\begin{abstract}
This article aims to present the transcription of the unpublished manuscript of a translation of Juvenal's tenth satire into Portuguese, undertaken in the mid-19th century by the Italian-Brazilian doctor, poet, professor and translator Luiz Vicente de Simoni (1792-1881). In addition to presenting the questions of textual criticism that contextualize the document, some comments will be made regarding the merit of the translation, contrasting it with the Portuguese version of Francisco Antonio Martins Bastos, a contemporary translator whose version is better known.
\end{abstract}

Keywords: Juvenal; poetic translation; Luiz Vicente de Simoni (17921881); diplomatic transcription.

Introdução

O trabalho que ora apresentamos é a transcrição, seguida de análise, de um manuscrito inédito do século XIX. Seu conteúdo é uma tradução poética da décima sátira do poeta latino Juvenal, vertida ao português por uma figura central para o estabelecimento dos Estudos Clássicos no Brasil, o médico e poeta italiano Luiz Vicente de Simoni. Este trabalho integra nosso projeto de pesquisa intitulado Podalírio nos trópicos, que investiga o acervo manuscrito deste intelectual para a recuperação de suas traduções do latim e para o latim, bem como de sua prática docente relacionada a esse idioma.

Luiz Vicente de Simoni foi uma das figuras mais interessantes e versáteis, ainda que sua atuação em diversos ramos das letras tenha sido quase que completamente esquecida pela posteridade, a transitar pela vida intelectual do Rio de Janeiro do período imperial.

1 Doutor em Letras (USP). Professor de língua e literatura latina do Departamento de Letras Clássicas e Vernáculas do Instituto de Letras da Universidade Federal Fluminense (UFF). Projeto de pesquisa: "Podalírio nos trópicos: estudo e edição de manuscritos de Luiz Vicente de Simoni”. 
Nascido $^{2}$ em 1792 em Novi, cidade a meio caminho entre o Piemonte e a Ligúria, cursou nessa cidade, no Colégio de São Jorge, os estudos primários, e formou-se em Medicina pela Universidade de Gênova em 1815. Pouco tempo depois de formado, partiu para o Brasil, onde chegou em 1817. Após uma breve e meritória estada na capital do reino, partiu para Moçambique, onde, de 1819 a 1821, exerceu o cargo de Físico-mor do reino. Regressando à corte ao fim desse período, estabeleceu-se como médico, profissão que exerceu por muitas décadas de sua longeva vida, tendo participado da fundação de diversas das instituições de prática e ensino da medicina do império nascente.

Ao lado de sua carreira médica, sempre se dedicou às letras, como testemunha a própria datação de alguns de seus manuscritos. Embora já viesse publicando e, principalmente, lendo seus textos em sessões públicas das agremiações que frequentava, poemas de sua lavra, sua projeção literária se consolida com Gemidos poéticos sobre os túmulos e Ramalhete poético do Parnaso Italiano, de 1842 e 1843, respectivamente, obras que mesclam composições próprias com traduções dos grandes poetas da literatura italiana. Como bem nota Heise (2007, p. 10), estudioso do Ramalhete, esta obra monumental é "a primeira e uma das únicas antologias de poesia italiana no Brasil até hoje”. A projeção que estes trabalhos lhe renderam permitiram que Simoni se dedicasse às letras de forma mais ampla: foi preceptor das filhas de D. Pedro II (que tinham mãe italiana) e a partir de 1858, integrou os quadros docentes do Colégio Pedro II, como docente de italiano e entre os anos de 1869 e 1876, de latim $^{3}$, quando sua cadeira foi extinta. Sua longa vida se encerrou em 1881, aos 89 anos.

Escritor de eloquência ciceroniana, produziu durante a vida uma vasta coleção de poemas próprios e traduções, tendo deixado materiais abundantes em sua língua vernácula, em português, em latim e em francês, sendo igualmente versado em todas essas línguas. Como bem recorda Stasio (2002, p. 122) Seu acervo pertenceu à Biblioteca Fluminense até 1916, quando foi transferido para a coleção de Manuscritos da Biblioteca Nacional.

Em que pese o impressionante volume de seu acervo e a diversidade de campos que ele cobre, sua atividade literária é amplamente desconhecida. Heise é o único pesquisador que até o presente se dedicou às traduções de Simoni na universidade, e seu enfoque é centrado nas traduções do italiano ao português (particularmente as de Dante). Sua produção relacionada ao latim, tanto poemas próprios quanto traduções de obras da latinidade para as línguas modernas, permanece desconhecida, dado que nunca foi dada à publicação e, além disso, se encontra dispersa pelas muitas pastas do acervo, por vezes junto a textos de natureza diversas, segundo critérios que não privilegiam sua condição de latinista.

O objeto cuja transcrição apresentaremos na sequência, contudo, tem características diferenciadas, que justificam nossa opção de começar a divulgação de suas traduções latinas por ela. Com efeito, a tradução de Juvenal faz parte da pasta inventariada sob o código I-07, 05, 017. Este item se diferencia pelo esmero com que foi organizado.

Enquanto outros itens reúnem, em geral, grande quantidade de documentos, a pasta I- $07,05,017$ contém quatro textos catalogados (na realidade, cinco, como veremos adiante), grandes extensões de poemas selecionados de quatro autores. Cada um desses textos se encontra separada um uma pasta menor dentro da pasta 017 , o que faz supor que se

2 Os dados biográficos aqui apresentados foram retirados de uma exaustiva relação de documentos, amplamente comentada, apresentada pelo autor em 1856 nos Annaes Brasilienses de Madicina, do qual, importa referir, Simoni foi um dos editores. ALMEIDA (2013, p. 267) faz equivalente recompilação dos dados biográficos.

3 Os dados referentes à atuação de Luiz Vicente de Simoni no CPII são retirados do Relatório das Repartições de Negócios do Império dos respectivos anos. Sua atuação como latinista será objeto da próxima etapa da pesquisa da qual este artigo faz parte. 
tratasse de uma coleção que o tradutor organizava para a publicação, ou que tenha sido assim entendida por algum dos organizadores desse acervo, quer na Biblioteca Fluminense, quer na Biblioteca Nacional. Sustenta a suposição de que fosse um projeto específico o fato de alguns desses itens conterem um rascunho inicial junto a uma versão passada a limpo, enquanto outros contêm apenas o rascunho ou a versão a limpo.

Os itens da pasta I-07, 05, 17 são: (001) Pérsio, Sátira 5, versos 19 a 72. Rascunho e versão a limpo. Interpolado ao rascunho de Pérsio, encontra-se uma versão de Ovídio, Metamorfoses, XI, 478ss. (Traducção de huma tempestade / de um dos livros das Metamorphoses / de Ovidio). O achado do texto indica um erro de catalogação, não de organização, dado que a folha de rosto do primeiro manuscrito indica "Versões de Horacio / Persio, Ovidio Juvenal / e / Outros Poetas Latinos" (Grifo nosso). ${ }^{4}$ (002) Juvenal, Sátira X (Os Votos), versos 1 a 55, apenas a versão a limpo. Este é o documento que apresentaremos na sequência. (003) Horácio, Sátiras, I, 8. Apenas o rascunho. Contem todos os cinquenta versos do poema. (004) Lívio Andronico, versão do "maior fragmento" do poeta. Trata-se de um par de dísticos elegíacos que hoje são preferencialmente atribuídos a Lévio. Este manuscrito em particular contém a transcrição dos quatro versos latinos junto à versão.

A tradução de Juvenal, em particular, é apresentada em duas folhas de papel almaço cortadas pela metade e utilizadas em sua parte superior. A tradução ocupa seis das oito faces disponíveis, tendo sido numerada pelo autor na extremidade superior externa (de 1 a 6). Os noventa e três versos da tradução estão distribuídos da seguinte forma: treze na página 1 , dezessete nas páginas 2,3 e 4 , dezesseis na página 5 e treze na página 6 . As duas laudas seguintes não foram ocupadas; supomos, da mesma maneira que o autor procede em outros manuscritos, que reservasse o espaço para as notas. Com efeito, ao longo do texto, o tradutor marca três passagens com parênteses ( ) que poderiam ter sido objeto de anotação.

Antes de procedermos à análise, apresentamos a transcrição semidiplomática do texto. Nossas intervenções no texto são mínimas, indicando apenas três substituições por sobreposição $(<>\mathrm{e} / \backslash)$, duas das quais ilegíveis $(\dagger)$. Acrescentamos também, para a comodidade do pesquisador que deseja confrontar a tradução a uma edição latina, a indicação aproximada da equivalência entre os versos da tradução e do original (5 a 5) dado que o tradutor não demonstra qualquer compromisso com homeometria (a disposição de sua tradução, aliás, será um dos aspectos abordados na discussão).

Transcrição de BNM I 07, 05, $017 \mathrm{n}^{\circ} 002$

fl $01 f$

1.

Juvenal

Satyra X. Os votos

Em quantas terras ha lá desde Cadis

Da Aurora até o berço e o rio Ganges,

Poucos os bens reaes distinguir podem

Dos que destes differem, afastada

A nuvem do erro; pois o que nós todos

4 Apresentamos a transcrição do fragmento ovidiano durante o I Colóquio Internacional sobre Ovídio, que teve lugar na Universidade de São Paulo em novembro de 2019, e deverá ter lugar em publicação próxima. 
Tememos com razão, ou desejamos?

O que emprehendes tu tão felizmente

Que não tenhas depois de arrepender-te

Desse esforço, e da supplica ja feitos?

Faceis em acceder aos desejantes

$O$, deuses deste modo derrubarão

Casas inteiras. Pedem-se lugares

Em que vestir-se a toga, e que nocivos

flo1v

2

Depois vão ser, e postos na milícia

Se pedem; que o serão da mesma forma.

Para muitos, fatal é sua própria

Facundia, e de fallar grande abundancia.

Aquelle pereceu em suas forças

Fiado, e nos seus braços admiraveis.

Porem a muitos tambem dão garrote

Dinheiro nimiamente acumulado

Com cuidado específico, e uma fortuna

Que a qualquer patrimonio immensa exceda

Quanto aos delphins balea da Britania.

Por isso encerrais tempos, por mandados

De Nero outrora uma cohorte inteira

A Longino encerrou, e os grandes hortos

Do riquissimo Seneca, e cercando

Agora está os grandes edificios

Dos Lateranos. Raro é soldado,

fl $02 f$

3

Chegue ao maior posto. () Se de noite

Empreenderes viagem, bem que leves

Pequeninos contigo, e poucos vasos

De pura prata, do bastão, da espada

Hás de tremer-te, e tremerás da sombra

De canna que ao luar movida seja.

Viaje o que consigo nada traga

Do ladrão na presença irá cantando.

Os votos principaes e conhecidos

De todos quasi são em quaesquer templos

Que as riquezas, e os teres vão crescendo

Para que em toda a praça o nosso cofre

Que outro qualquer que haja o maior seja.

Mas acónito algum não é bebido

Em vasilha de barro. Tu só delle

162 - Conexão Letras, Porto Alegre, v. 15, n. 24, p. 159-171, jul-dez. 2020. 
Receio tenha quando em taças pegues

De pedras preciosas adornadas;

fl $02 v$

4

Ou quando em ouro largo ardendo esteja. ()

Vinho de Secia. Louvas já portanto

Talvez que de dous sabios o segundo

Se risse cada vez que elle percebe

O pé fora da porta, fosse andando

E que ao outro ao contrário então chorasse.

Mas fácil a qualquer é a censura

Da forte gargalhada. É de admirar-se

Que o humor não faltasse aos olhos delle.

Com um riso perpétuo $<\dagger>/$ soía $\mid$

Democrito agitar sempre seu bofe;

Bem que nessa cidade não houvesse

Pretexta, tribunal, trabeas nem fasces

Nem liteira. O que passa se ele visse

$O$ pretor 'stando em pompa em alto carro

Do pó do circo torrear no meio

Em tunica de Jupiter, trazendo

$f 03 f$

5

De tyrias cores um pintado manto

Sobre a toga no hombro pendurado

E de coroa um circulo tão grande

Que pescoço nenhum aguentaria?

Pois que um publico servo conduzido

No mesmo carro ao consul admoesta

Para que mude se lhe não compraza.

Acrescenta tu agora essa na ponta

Do eburneo sceptro ave <que surge> /alteantele n'uma

Ponta as cornetas, n'outra de obsequente

Bando uma longa precedencia e junto

Dos freios caminhando em niveo traje

Os Quirites que amigos for a esportula

Encovada em seus fundos encaminhas.

Também então de riso achou materia

Esse sabio em qualquer d'homens encontra

fl $03 v$

6

E o riso d'elle mostra que na patria

Dos carneiros capados, em um crasso 
Homens sumos tem poder, nascimento

Que depois dêm de si grandes exemplos.

Dos cuidados do vulgo ele se ria

E dos jubilos d'elles, e por vezes

Das lagrimas tambem quando um $<\uparrow>/$ baraçol

À fortuna minar mandava, e o dedo

Protendendo assim figas lhe fazia.

Portanto, inutilmente, ou com perigo

Estas cousas se pedem com que crê-se

Ser lícito, com cera pendurada ()

Ir carregando aos deuses os joelhos.

Apresentamos abaixo uma versão simplificada, com atualização ortográfica e de pontuação, bem como com remoção das notações:

Juvenal

Satyra X. Os votos

Em quantas terras há lá desde Cadis

Da Aurora até o berço e o rio Ganges,

Poucos os bens reais distinguir podem

Dos que destes diferem, afastada

A nuvem do erro; pois o que nós todos

Tememos com razão, ou desejamos?

O que empreendes tu tão felizmente

Que não tenhas depois de arrepender-te

Desse esforço e da súplica já feitos?

Fáceis em aceder aos desejantes,

Ó, deuses deste modo derrubaram

Casas inteiras. Pedem-se lugares

Em que vestir-se a toga, e que nocivos

Depois vão ser, e postos na milícia

Se pedem; que o serão da mesma forma.

Para muitos, fatal é sua própria

Facúndia e de falar grande abundância.

Aquele pereceu em suas forças

Fiado e nos seus braços admiráveis.

Porém a muitos também dão garrote,

Dinheiro nimiamente acumulado

Com cuidado específico e uma fortuna

Que a qualquer patrimônio imensa exceda

Quanto aos delfins baleia da Britânia.

Por isso encerrais tempos, por mandados

De Nero outrora uma coorte inteira

A Longino encerrou, e os grandes hortos

Do riquíssimo Seneca, e cercando 
Agora está os grandes edificios

Dos Lateranos. Raro é soldado,

Chegue ao maior posto. Se de noite

Empreenderes viagem, bem que leves

Pequeninos contigo, e poucos vasos

De pura prata, do bastão, da espada

Hás de tremer-te, e tremerás da sombra

De cana que ao luar movida seja.

Viaje o que consigo nada traga

Do ladrão na presença irá cantando.

Os votos principais e conhecidos

De todos quase são em quaisquer templos

Que as riquezas e os teres vão crescendo

Para que em toda a praça o nosso cofre

Que outro qualquer que haja o maior seja.

Mas acônito algum não é bebido

Em vasilha de barro. Tu só dele

Receio tenha quando em taças pegues

De pedras preciosas adornadas;

Ou quando em ouro largo ardendo esteja

Vinho de Sécia. Louvas já portanto

Talvez que de dous sábios o segundo

Se risse cada vez que ele percebe

O pé fora da porta, fosse andando

E que ao outro ao contrário então chorasse.

Mas fácil a qualquer é a censura

Da forte gargalhada. É de admirar-se

Que o humor não faltasse aos olhos dele.

Com um riso perpétuo soía

Demócrito agitar sempre seu bofe;

Bem que nessa cidade não houvesse

Pretexta, tribunal, trábeas nem fasces

Nem liteira. O que passa se ele visse

$\mathrm{O}$ pretor 'stando em pompa em alto carro

Do pó do circo torrear no meio

Em túnica de Jupiter, trazendo

De tírias cores um pintado manto

Sobre a toga no ombro pendurado

E de coroa um círculo tão grande

Que pescoço nenhum aguentaria?

Pois que um público servo conduzido

No mesmo carro ao cônsul admoesta

Para que mude se lhe não compraza.

Acrescenta tu agora essa na ponta

Do ebúrneo cetro ave alteante e numa

Ponta as cornetas, noutra de obsequente 
Bando uma longa precedência e junto

Dos freios caminhando em níveo traje

Os Quírites que amigos for a espórtula

Encovada em seus fundos encaminhas.

Também então de riso achou matéria

Esse sábio em qualquer de homens encontra

E o riso dele mostra que na pátria

Dos carneiros capados, em um crasso

Homens sumos têm poder, nascimento

Que depois deem de si grandes exemplos.

Dos cuidados do vulgo ele se ria

E dos júbilos deles, e por vezes

Das lágrimas também quando um baraço

À fortuna minar mandava e o dedo

Protendendo assim figas lhe fazia.

Portanto, inutilmente, ou com perigo

Estas cousas se pedem com que crê-se

Ser lícito, com cera pendurada

Ir carregando aos deuses os joelhos.

\section{Discussão}

A primeira característica que salta da tradução em questão é o enfoque do tradutor em uma exposição clara dos termos traduzidos, não hesitando em recorrer a termos longos e a construções analíticas ('inutilmente' ou 'ir carregando' por exemplo) com vistas a evitar disposições complicadas de termos ou obscuridade. Essa característica pode ser observada no confronto do original latino, por exemplo, do primeiro período do texto (v. 1 a 5). Para facilitar o contraste, numeramos certas unidades de sentido que facilitam a visualização dos procedimentos tradutológicos de Simoni:

(1. Omnibus in terris), (2. quae sunt a Gadibus) (3. usque

Auroram et Gangen), (4. pauci) (5. dinoscere possunt)

(6. uera bona) (7. atque illis multum diuersa), (8. remota

erroris nebula). (9. quid enim) (10. ratione timemus)

(11. aut cupimus)?

(1. Em quantas terras) (2. há lá desde Cadis)

(3. Da Aurora até o berço e o rio Ganges),

(4. Poucos) (6. os bens reais) (5. distinguir podem)

(7. Dos que destes diferem), (8. afastada

A nuvem do erro) ; (9. pois o que) nós todos

(10. Tememos com razão), (11. ou desejamos)?

No princípio do poema, o tradutor opera uma concisão bem engenhosa que faz caber o primeiro verso latino praticamente inteiro no primeiro decassílabo. Com efeito, o primeiro 
sintagma, omnibus in terris, se traduziria mais precisamente por 'Em todas as terras', expressão que se encaixa mal no ritmo do decassílabo; quando o tradutor a substitui por 'Em quantas terras', não apenas resolve a questão do ritmo, permitindo a acentuação da quarta sílaba (para um verso sáfico) e não ocupando a sexta sílaba com uma sílaba átona (o que tornaria um verso heroico impossível), mas também elimina a necessidade da subordinação da oração compreendida, no original, pelos grupos (2) e (3), introduzida pela conjunção quae.

Embora esse começo aponte para um resultado conciso, o objetivo do tradutor não é sintetizar o português, mas usá-lo harmoniosamente, de modo que o segundo verso da tradução, ao contrário do primeiro, é copioso, abrigando apenas os sintagmas que integram o grupo (3). Além disso, para que o verso tivesse o resultado que deseja, transformou Auroram em 'berço da Aurora', eliminando a metonímia do original, e acrescentou o especificador 'rio' ao nome próprio Ganges. A solução não só tenta criar um verso eufônico como, sendo explicativa, se antecipa a problemas de interpretação e elimina a necessidade de notas como as que, inferimos, eram previstas em outras passagens dessa tradução.

Sua sensibilidade ao efeito estético do latim e à possibilidade de achar equivalências em português podem ser vistos nos versos seguintes, quando, por exemplo, mantém a ordem dos termos do grupo (5) dinoscere possunt, 'distinguir podem', mesmo que essa ordem seja direta para o latim mas indireta para o português. A colocação desse grupo, que está no final do verso latino, no final do verso em português demonstra que essa é uma das preocupações estéticas, visto que, nesse caso em particular, o resultado da tradução é desagradável em português, colocando um acento na sílaba anterior à tônica final do verso e, com isso, comprometendo sua cadência. Um exemplo de passagem em que essa preocupação tem resultado sonoro é com o grupo (8).

Os procedimentos do autor, incluem, por exemplo, a remoção de multum da tradução do grupo (7), uma reinterpretação de (6) uera bona, 'as verdadeiras coisas boas', em 'os bens reais', no acréscimo do pronome 'nós', cujo caráter analítico se intensifica com o adjetivo 'todos', e finalmente com a elegante distribuição do grupo (8), entre o fim de um verso e o começo do outro, na mesma disposição verificada no latim, na qual o termo 'remota', 'afastada', efetivamente se afasta de seu objeto por meio da quebra do verso.

Da adoção de critérios primordialmente analíticos resulta que a razão de versos da tradução para os do original seja de 1,66 (55 hexâmetros vertidos em 93 decassílabos). Isto é, cada hexâmetro latino ocupa, em média, um verso e mais dois terços de um segundo verso. São valores um pouco mais elevados do que a média proposta por Thamos (2011, p. 206) de 1,4 decassílabos para cada hexâmetro, resultante de seu confronto entre os números de sílabas de um e outro metro e por ele verificado, por exemplo, na tradução das Metamorfoses de Ovídio por Bocage.

Em que pese o aporte estatístico, a observação do texto mostrará que não há regularidade nessa distribuição de informações pelos versos. A título de exemplo, é de se notar que os quatro versos e meio iniciais do original latino se estendem com bastante concisão por seis decassílabos, ao passo que os versos 51 a 55 do original ocupam nove longos decassílabos.

Pelo que se disse até aqui, deve-se descartar qualquer tentativa de encontrar homeometria. Com efeito, essa preocupação seria anacrônica na tradução de poesia latina no século XIX. Ao mesmo tempo, a investigação da atuação tradutológica de Luiz Vicente de Simoni é preciosa pois permite contrastar sua atuação de italianista com a de latinista. Como bem lembra Heise (2007, p. 29), tratando do Ramalhete poético do parnaso italiano: 
No frontispício (foi feita a atualização ortográfica) encontramos os dizeres: "esta pequena coleção de trechos de alguns dos melhores poetas italianos, homeometricamente vertidos". Mas não era o bastante imprimir no frontispício o termo "homeometricamente" para entender-se que se tratava de tradução literal. Nas primeiras páginas do livro há um soneto que expressa claramente a aversão do tradutor em relação à França.

Assim, para Simoni é prioritário manter padrões estróficos, métricos e de rima de sonetos, tercetos, canções, odes e oitavas-rimas do volumoso corpo de poetas italianos que reúne em sua coleção. Isso, nos parece, se justifica pelo fato de que, na maior parte de sua existência, o sistema de signos estéticos das línguas italiana e portuguesa serem praticamente idênticos: desde que Sá de Miranda introduz o dolce stil nuovo em Portugal, em 1527, os padrões estilísticos italianos são acolhidos emulados pelos portugueses. Nesse sentido, é prioritário que um soneto petrarquiano, por exemplo, se apresentasse como soneto em uma língua que já identificava esse signo estético pela versatilidade e excelência de nomes como Camões, Gregório de Matos ou Bocage.

Quando, porém, se passa à inter-relação dos signos estéticos latinos e vernáculos, tal discussão é menos produtiva e, pelo que se vê no amplo repertório de traduções que já existia até então, menos problematizada. O decassílabo reina como forma virtualmente única de traduzir a literatura latina hexamétrica e a não-correlação dos metros latinos a este metro vernáculo é tão evidente que o problema demora a ser posto. Tanto quanto já pudemos apurar nas traduções latinas do médico italiano com as quais já tivemos contato, essa preocupação, central para a tradução da poesia italiana, não se aplica à poesia latina, sendo substituída por outras prioridades, como a da distribuição de determinados elementos rítmicos do original à tradução, como vimos antes.

Outro aspecto digno de nota é o fato de o tradutor apresentar apenas uma seleção de cinquenta e cinco versos do poema de Juvenal, parcela pequena dos 366 que são a íntegra da sátira X. Não havendo nenhuma explicação, apenas nos cabe formular conjecturas, em especial sustentadas pelo confronto com os outros objetos da pasta I-017.

Posto de lado o breve fragmento de Lévio, o único texto integral da coleção é a sátira 8 de Horácio, que tem exatos cinquenta versos. Pérsio também é apresentado em um excerto, dos versos 19 a 72, cinquenta e três versos, portanto. A uniformização dos excertos, que variam entre cinquenta e cinquenta e cinco versos, poderia indicar uma eventual publicação na imprensa ou em alguma coleção seriada, para a qual seria necessário submeter um volume limitado de texto.

Essa hipótese pode ser corroborada pela forma como o autor recorta a sátira de Pérsio. Esse poema, com efeito, tem algumas divisões internas que resultam inclusive numa transição brusca de assuntos. Ao começar no verso 19, Simoni elimina de sua tradução a parte introdutória do poema, em que Pérsio faz um circunlóquio sobre como vai abordar o tema principal, contendo complicadas alusões a passagens literárias da poesia épica e trágica. A tradução parte do ponto em que, definido seu estilo, o poeta começa a matéria principal do poema, seus anos de formação junto ao filósofo Cornuto. O recorte ao fim também se adianta à maioria das voltas complicadas que Pérsio dá ao longo do resto do poema.

Tudo isso poderia indicar que tais textos tivessem como destinatário um público mais amplo e menos especializado, para quem o excesso do gênero satírico e o rigor técnico das anotações pudesse ser indesejado e, por isso, constrangesse o tradutor a expandir seu texto.

A prática do alongamento e da inclusão do elemento explicativo no corpo da tradução, por si só, não é nova: como aponta Lohner (2018, p. 241), já pode ser verificada na 
tradução setecentista do Édipo de Sêneca por Cândido Lusitano (1719-1773), na qual “o estilo conciso empregado por Sêneca é substituído por uma tradução que explicita dados contextuais e as relações lógicas implícitas nas expressões apositivas da frase latina, especialmente as de valor antitético". Tal análise é igualmente aplicável às Metamorfoses de Ovídio do mesmo tradutor.

Como lembra Mello (2019, p. 45), observando o tradutor pela perspectiva da Análise do Discurso, "Os movimentos de tomada de posição do sujeito no discurso têm relação tanto com a historicidade quanto com o caráter singular do inconsciente". Ao tentarmos supor as motivações do tradutor, tão cioso de explicar suas motivações em suas obras publicadas em vida, podemos pressupor um controle e uma consciência sobre o texto que ele próprio não tinha durante o processo. Apesar disso, o confronto que pretendemos fazer com a tradução mais conhecida de Juvenal para o português argumentará entre outras coisas para o fato de que, embora não tenham sido descritas localmente, essas escolhas eram conscientes do autor.

Para efeito de contraste, portanto, vejamos na sequência a tradução de Martins Bastos para os versos iniciais do mesmo poema, bem como alguns dos princípios que norteiam suas escolhas.

Francisco Antonio Martins Bastos (1799-1868) foi um poeta e latinista português, que publicou poesia própria tanto na língua clássica quanto na vernácula, embora tenha se destacado prioritariamente pelas traduções de Juvenal que, ao menos no Brasil, tem sido sistematicamente reimpressas pela Tecnoprint/Ediouro.

Esta tradução, vinda à luz pela primeira vez em 1839, é motivada pela admiração que Martins Bastos nutre pelo poeta, clara já no início de seu prefácio, quando declara que "traduzir hum autor, he a prova mais decidida que se pode dar da estimação, que dele se faz" (JUVENAL, 1839, iv).

No entanto, o juízo que o tradutor forma do tradutor, que envolve nobreza (p. vi), o ouvir o clamor da miséria de todos os tempos (p. vii-viii), tanto mais notável quanto mais ignorado por outros, o envolve numa aura de solenidade que não combina com as tintas grotescas que são observáveis nos versos. Preso à necessidade pouco clássica de associar pessoa e persona, Martins Bastos é constrangido a julgar o baixo calão e as imagens chocantes, mas se considera melhor que seus predecessores ao seguir "diverso caminho: mudei a luz ao quadro, de sorte que mais se bruxeleão os objectos, do que se mostrão". (p. xxii).

Mais deletéria, contudo, é a forma como o entendimento do estilo interfere na tradução. Martins Bastos contesta aqueles autores que dizem que Juvenal "escrevera em estylo Oratorio, talvez esquecendo-se que neste genero de Poesia não pode entrar a pompa da estrondosa Epopeia." (p. xxii). Três conceitos que não se sobrepõem de forma apropriada são confrontados na afirmação, a saber, os gêneros épico e satírico e uma associação do primeiro ao estilo oratório. A associação é problemática, mas faz entrever que o autor assume em relação à poesia épica um grau de solenidade, ou de articulação de figuras, característico da oratória (mas de qual?), às epopeias, esquecendo que a indignação satírica é tão discursiva quanto a solenidade épica, não caracterizando portanto um gênero mais sincero que o outro, ou menos afeito à construção, mas tão-somente uma diferença de afetos.

Dessa forma, o bruxulear dos objetos e a anti-oratória quixotesca que o tradutor enxerga em Juvenal levam a uma tradução seca do poema, como se pode perceber nos mesmos versos iniciais da sátira $\mathrm{X}$ que analisamos acima. Para maior comodidade, repetimos o texto latino dividido nos mesmos grupos que usamos para analisar a tradução de Simoni: 
(1. Omnibus in terris), (2. quae sunt a Gadibus) (3. usque

Auroram et Gangen), (4. pauci) (5. dinoscere possunt)

(6. uera bona) (7. atque illis multum diuersa), (8. remota

erroris nebula). (9. quid enim) (10. ratione timemus)

(11. aut cupimus)?

(2. De Cadis) (3. té ao Ganges), (4. homens poucos),

(6. Do vero bem), (7. o mal oposto) (5. extremam),

(8. De Prejuízos livres). (9. Quantas coisas)

(10. Se temem com razão), (11. ou se apetecem)

Na sua tradução, vemos a supressão do grupo (1), a amputação de um dos elementos de (3), a interpretação muito livre do grupo (5), vertendo o 'saber distinguir' pelo muito menos óbvio 'extremar', a mudança injustificada de (8) 'afastada a nuvem do erro' para 'De prejuízos livres' e finalmente a mudança de verbos ativos na primeira pessoa do plural em (10) e (11) para a voz passiva sintética.

Fica evidente, e o próprio tradutor chega a afirmá-lo em seu prefácio, que a versão tem passagens de "demasiada liberdade" (p. xxii). Que este seja um critério, e deixado às claras, não é um problema por si só: compromete a qualidade da versão que essa liberdade muitas vezes resulte em escolhas inferiores de sentido - para não falar no deletério de determinadas omissões.

Veja-se por exemplo que o poeta, nos grupos (1) a (3) está circunscrevendo geograficamente todo o mundo conhecido pelos romanos, de oeste a leste, da Espanha à Índia, e estende essa amplidão por mais de um verso justamente para contrastar com a exiguidade dos homens sábios. É uma amplificação cujo efeito é destruído quando se opta por uma tradução econômica, que ao menos não suprime também as assonâncias em 'Cádis' e 'Ganges'.

Igualmente, poderíamos discutir a reinterpretação de 'remota / erroris nebula', literalmente 'afastada / a nuvem do erro', que Martins Bastos troca por um pouco oportuno 'de Prejuízos livre'. Ao proceder dessa forma, despreza as conotações do termo nuvem, incluído aqui o uso prévio do termo pelos antecessores satíricos de Juvenal (Horácio, $A P$, 230 e Pérsio, 5, 7), ou ainda a ỏ $\tau$ pía, cujo significado literal é 'ausência de fumaça', conceito filosófico importante pois indica o estado de clareza do espírito almejado por determinadas escolas filosóficas da antiguidade, em que a mente está desobstruída de coisas que a impedem de ver (a fumaça). Não é casual que ao verbo tú $\varphi \omega$, fazer fumaça,

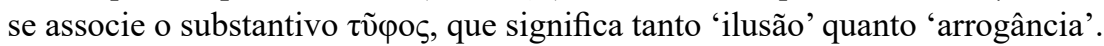

A secura do texto de Martins Bastos, como se pode ver, é deletéria, uma vez que despreza a noção de que a sátira é um gênero da abundância: não apenas determinados vícios são comentados nesse gênero, mas sua exposição deve ser levado à exaustão, saturada, por assim dizer.

\section{Conclusão}

Retomando a exposição prévia e à guisa de conclusão, parece-nos que o movimento do sujeito-tradutor Simoni, em especial contrastado aos procedimentos de Martins Bastos, tende ao historicizável e ao consciente: o italiano demonstra ampla familiaridade 
com o repertório satírico, como é verificável em seu acervo manuscrito (STASIO, 2002). Seus papéis didáticos dão conta do amplo uso dos poetas satíricos latinos em sala de aula, há traduções inéditas de sátiras latinas e italianas em seu acervo, mas, principalmente, há muitos poemas próprios classificados como satíricos, alguns dos quais parcialmente transcritos por Almeida (2013). Desse conhecimento e dessa prática no gênero satírico resultam as escolhas do tradutor por um texto escorreito, em que o quadro claro, não obscuro, será a finalidade do texto.

\section{Referências}

ALMEIDA, Anita C. L. de. Medicina em versos no Rio de Janeiro oitocentista: os escritos de Luís Vicente de Simoni. Revista Brasileira de História da Ciência, Rio de Janeiro, v. 6, n. 2, jul./dez. 2013, p. 267-282.

CARMO, Rafael C. Difficile est saturam bene vertere: os desafios da tradução poética e uma versão brasileira das sátiras de Juvenal. 2018. Tese (Doutorado em Letras) - Centro de Ciências Humanas e Naturais, Universidade Federal do Espírito Santo. Vitória, p. 291. 2018.

HEISE, Pedro F. A introdução de Dante no Brasil: o "Ramalhete poético do Parnaso Italiano", de Luiz Vicente de Simoni. 2007. Dissertação (Mestrado em Letras) Faculdade de Filosofia e Ciências Humanas, Universidade de São Paulo. São Paulo, p. 102. 2007.

JUVENAL. As satyras de Décio Junio Juvenal, principe dos poetas satyricos. Lisboa: Imprensa de Cândido Carvalho, 1839. Tradução de Francisco Antonio Martins Bastos.

. Sátiras. Rio de Janeiro: Ediouro, 1991. Tradução de Francisco Antonio Martins Bastos.

. Satiren. Herausgegeben, übersetzt und mit Anmerkungen versehen von Joachim Adamietz. Zürich: Arternis und Winkler, 1993.

LIDDEL, Henry G.; SCOTT, Robert. Greek-English Lexicon. Oxford: Clarendon Press, 1940 .

MELLO, G. C. C. Os movimentos discursivos do sujeito-tradutor. In: PAGANINE, Carolina; HANES, Vanessa. Tradução e criação: entrelaçamentos. Campinas: Pontes, 2019.

PREDEBON, Aristóteles A. Edição do manuscrito e estudo das Metamorfoses de Ovídio traduzidas por Francisco José Freire. 2006. Dissertação (Mestrado em Letras)

- Faculdade de Filosofia e Ciências Humanas, Universidade de São Paulo. São Paulo, p. 850. 2006.

SÊNECA, Tiestes. Curitiba: UFPR, 2018. Tradução, notas e estudos de José Eduardo S. Lohner.

STASIO, Angela di. Coleções de manuscritos literários no acervo da Biblioteca Nacional. Anais da Biblioteca Nacional, v. 122, 2002, p. 59-290.

THAMOS, Márcio. Do hexâmetro ao decassílabo: equivalência estilística baseada na materialidade da expressão. Scientia Traductionis, n. 10, 2011, p. 201-213.

Recebido em: 14/05/2020; Aceito em: 21/05/2020. 